\title{
Periodic Discharges in Herpes Encephalitis Presenting with Non-convulsive Status Epilepticus: A Detailed Demonstration of the Temporal Correlation Between EEG and Neurologic Status
}

\author{
Non-konvülzif Status Epileptikus ile Başvuran Herpes Ensefalitinde Periyodik Deşarjlar:
} EEG ve Nörolojik Durumu Arasındaki Zamansal İlişkinin Ayrıntılı Illlüstrasyonu

\author{
(1) Halil Önder ${ }^{1}$, (1) Fatih Temoçin ${ }^{2}$ \\ ${ }^{1}$ Yozgat City Hospital, Clinic of Neurology, Yozgat, Turkey \\ ${ }^{2}$ Yozgat City Hospital, Clinic of Infectious Diseases and Clinical Microbiology, Yozgat, Turkey
}

Keywords: Periodic discharges, non-convulsive status epilepticus, EEG, herpes encephalitis, pathophysiology

Anahtar Kelimeler: Periyodik deşarjlar, non-konvülzif status epileptikus, EEG, herpes ensefalit, patofizyoloji

\section{Dear Editor,}

A 62-year-old female patient presented to our emergency department due to fever and unconsciousness, which had gradually progressed over the last three days. Her medical history was unremarkable. At admission, vital signs revealed a fever of $38.7^{\circ} \mathrm{C}$. In a neurologic examination, the patient was evaluated as lethargic. She could give a verbal response as incomprehensible sounds and could not cooperate constantly. Kernig's and Brudzinski's signs were negative. Laboratory examinations showed mild leukocytosis (white blood cells: 12,400/dL, hemoglobin: $11.8 \mathrm{~g} / \mathrm{dL}$, platelets: $400,000 / \mathrm{dL}$, C-reactive protein: $2.18 \mathrm{mg} / \mathrm{L}$ ); other investigations including blood biochemistry, vitamin B12, and folic acid were within the normal limits. Diffusion-weighted imaging (DWI) was performed in the acute period, which showed high signal on DWI and an isointense signal on apparent diffusion coefficient sequences in the left temporal lobe, which was compatible with vasogenic edema (Figure 1). We attempted lumbar puncture (LP) twice, but failed due to technical problems. Therefore, with a preliminary diagnosis of encephalitis, broad-spectrum therapy of intravenous acyclovir $3 \times 750 \mathrm{mg}$, ceftriaxone $2 \times 2 \mathrm{~g}$ and ampicillin $4 \times 3 \mathrm{~g}$ were initiated in the emergency department and the patient was hospitalized for follow-up and administration of maintenance therapy. In the following course, the neurologic examination of the patient was stable; however, on the third day of hospitalization, she had a generalized tonic- clonic seizure. Intravenous $5 \mathrm{mg}$ diazepam was administered, which provided cessation of seizure and the patient was transferred to our intensive care unit. However, she had one more generalized tonic-clonic seizure one hour later. After a prompt neurologic assessment, valproic acid $2 \times 500 \mathrm{mg}$ was initiated. It was a weekend and an electroencephalography (EEG) technician was not on duty. Hence, EEG was planned to be performed two days later within working hours. Nevertheless, a significant deterioration in the patient's neurologic status was recognized soon after the seizures, such that she could only open her eyes to painful stimulus, there was no motor response, but a verbal response could be obtained (Glasgow Coma Score: 4). The third attempt of LP was successful and cerebrospinal fluid (CSF) investigations showed mild protein elevation $[47 \mathrm{mg} / \mathrm{dL}$ (normal: 15-45)], and normal glucose levels. CSF microscopy examinations showed leukocytes as $180 / \mathrm{mm}^{3}$ and erythrocytes $50 / \mathrm{mm}^{3}$ supporting the diagnosis of encephalitis. Contrastenhanced magnetic resonance imaging (MRI) was recorded on the $4^{\text {th }}$ day of hospitalization, which revealed an edematous lesion in the left uncus of the parahippocampal gyrus, anterior temporal lobe, and posterior part of the frontal lobe (Figure 2). EEG could be performed on the next day (5th day) of hospitalization, which showed a severe slowing of the background activity and $1.5-2 \mathrm{~Hz}$, generalized, asymmetric, periodic discharges (PD) (GPD) in the bilateral hemisphere (Figure 3). With the possible diagnosis of non-

\footnotetext{
Address for Correspondence/Yazıșma Adresi: Halil Önder MD, Yozgat City Hospital, Clinic of Neurology, Yozgat, Turkey Phone: +90 3544442066 E-mail: halilnder@yahoo.com ORCID: orcid.org/0000-0002-1823-2278

Received/Geliş Tarihi: 31.01.2019 Accepted/Kabul Tarihi: 08.05.2019

${ }^{\circ}$ Copyright 2019 by Turkish Neurological Society

Turkish Journal of Neurology published by Galenos Publishing House.
} 

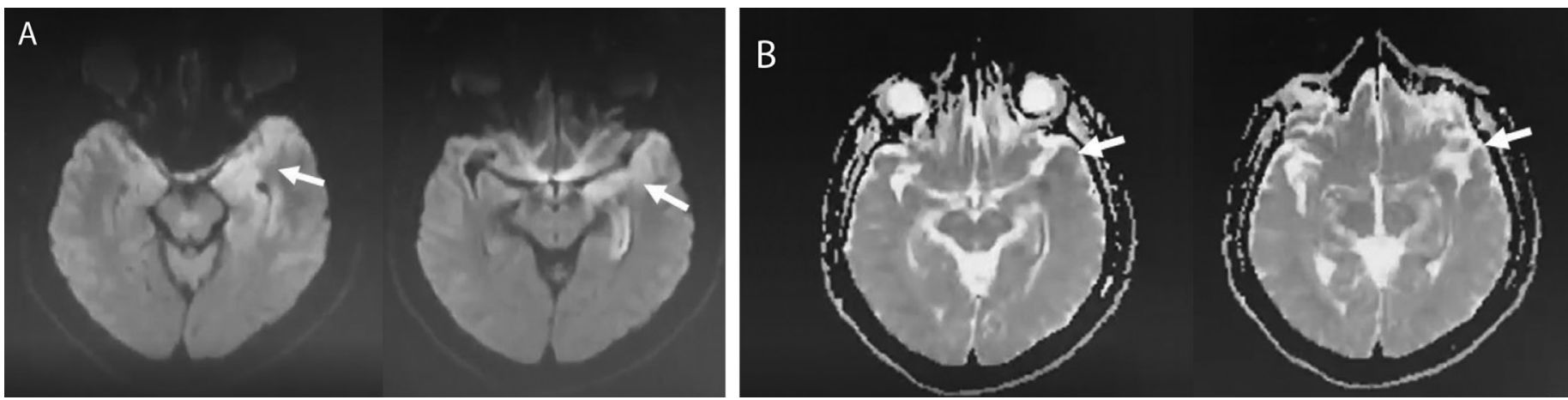

Figure 1. Diffusion-weighted imaging (DWI) and apparent diffusion coefficient (ADC) images recorded at admission in emergency service. A) A high signal in DWI in the in the left uncus of the parahippocampal gyrus, anterior temporal lobe. B) However, ADC images did not show low signal in the corresponding regions supporting underlying vasogenic edema (arrows)

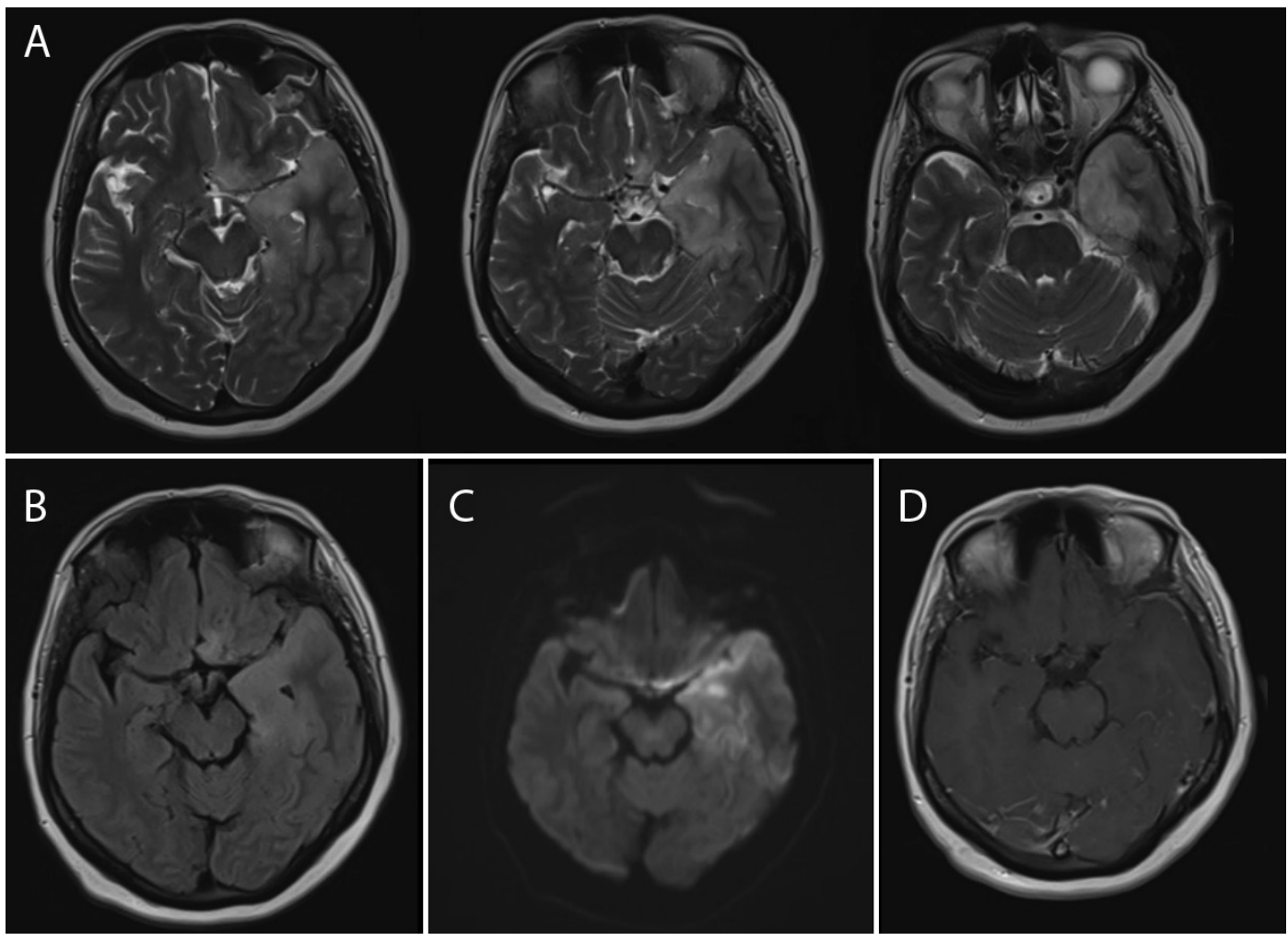

Figure 2. Contrast-enhanced magnetic resonance imaging performed on the $4^{\text {th }}$ day of admission (one day after the seizure), showing edematous lesion in the left uncus of the parahippocampal gyrus, anterior temporal lobe, posterior part of the frontal lobe (arrows)

convulsive status epilepticus (NCSE), phenytoin $18 \mathrm{mg} / \mathrm{kg}$ was administered and maintenance anti-epileptic therapy was adjusted as valproic acid 2x1000 mg, 3x100 mg phenytoin, and levetiracetam 2x750 mg. A significant improvement in the neurologic status was achieved and the neurologic examination on the next day ( $6^{\text {th }}$ day of hospitalization) showed that the patient could open her eyes to verbal commands and leftsided paralysis had recovered such that she could localize pain with her left hand. Concurrently performed EEG showed a moderate improvement in the background activity (up to theta activity) and resolution of PD in the right hemisphere (Figure 4). Anti-epileptic treatments (AET) were increased as valproic acid 2x1000 mg, 3x100 mg phenytoin, levetiracetam $3 \times 1000 \mathrm{mg}$, and carbamazepine $2 \times 400 \mathrm{mg}$ was also added. EEG recorded two days later showed significant resolution in the lateralized periodic discharge (LPD) activity and an increase of the background activity up to $7 \mathrm{~Hz}$ (Figure 5). EEG that was recorded two weeks later showed $9 \mathrm{~Hz}$ parietooccipital alpha activity and total resolution of the LPD activity (Figure 6). A neurologic examination performed on the same day showed 


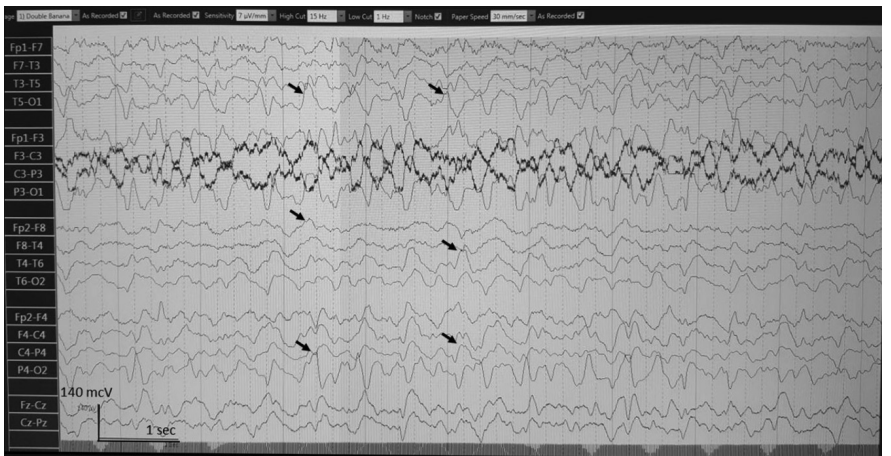

Figure 3. Electroencephalography, which was performed two days after the seizures, showed generalized periodic discharges at $1.5-2 \mathrm{~Hz}$ and slowing of the background activity (arrows)

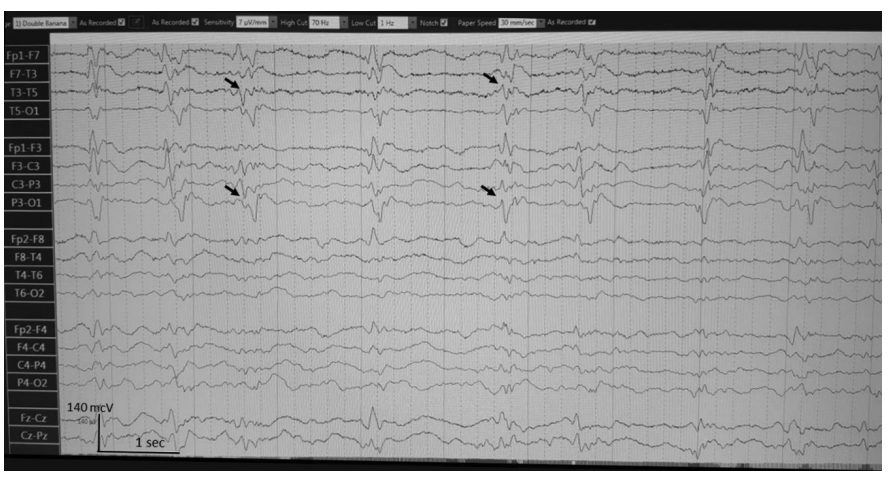

Figure 4. Electroencephalography, recorded the next day, showing a moderate improvement in the background activity (up to theta activity) and resolution of periodic discharges in the right hemisphere

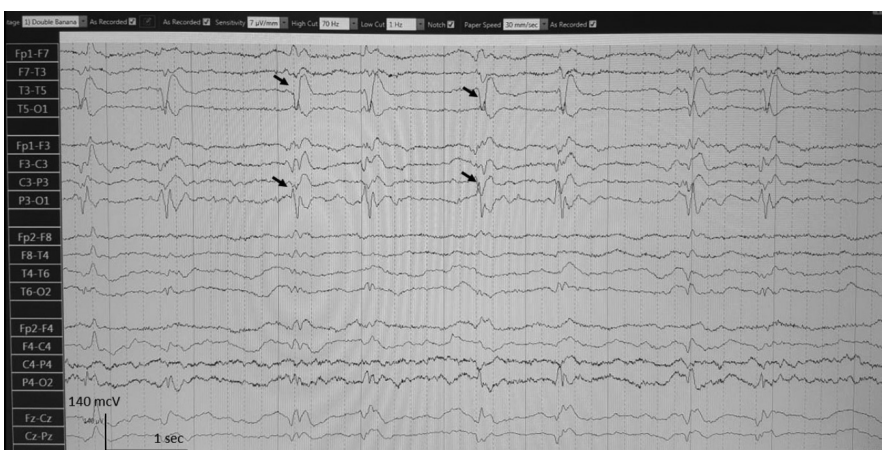

Figure 5. Electroencephalography, performed after two days, showing the limitation of periodic discharges in the left parietocentral areas (arrows)

that the patient was totally orientated and cooperated. Other investigations including motor, cerebellar, and sensory were within normal ranges. However, she had memory problems, and poverty of speech content was recognized. Meanwhile, CSF polymerase chain reaction testing confirmed the diagnosis of Herpes simplex virus type 1 encephalitis and acyclovir was continued for up to 21 days. Follow-up cranial MRI, performed 4 weeks after admission, showed resolution in the expansion of the lesion in the left temporal lobe (Figure 7).

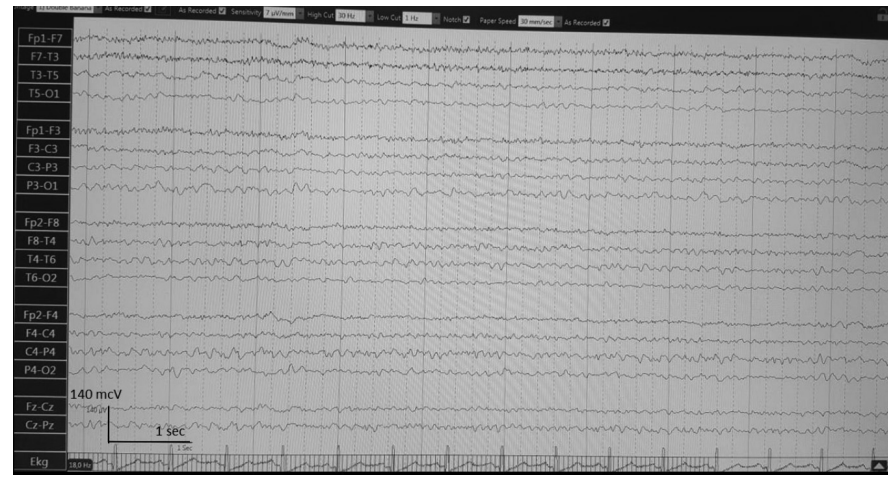

Figure 6. Electroencephalography, performed 2 weeks later, showing $9 \mathrm{~Hz}$ parietooccipital alpha activity and totally resolution of lateralized periodic discharges (the discharges are decreasing in amplitude, the repetition rate decreases and then the discharges cease)

\section{Discussion}

Periodic EEG patterns describe various forms of discharges, usually epileptiform in appearance, and apply to waves or complexes occurring in sequence at an approximately regular rate or intermittently regular intervals (1). PD should suggest the underlying possible seizures and convulsive status epilepticus or NCSE, and many researchers recommend the initiation of AET to manage the occurrence of these discharges (2). However, the ictal significance of PD is still under debate as many other conditions other than an underlying ictal events (e.g. irreversible hypoxic brain, mental retardation, metabolic encephalopathies, Creutzfeldt-Jakob disease) may manifest with GPEDs. That is why the American Clinical Neurophysiology Society proposed the term 'LPD' to name PLEDs, 'bilateral independent PD' to name bilateral independent periodic lateralized epileptiform discharges, and 'generalized PD' to name GPDs (3). From the pathophysiologic point of view, it has been hypothesized that LPDs could be the EEG manifestation of an abnormal response of neurons, occurring due to changes in their excitatory neurotransmission in cases of acute brain injury (4).

In a recent crucial report, synaptic failure or neuronal damage of inhibitory interneurons, leading to disinhibition of excitatory pyramidal cells was proposed as the responsible mechanism of GPDs. The authors also hypothesized that reversibility might depend on the functional recovery of these neurons, which cannot be available in some circumstances. In conclusion, the authors also indicated that there was still uncertainty asto whether AETs were helpful in regaining this function (5). Ergo, their (PD) clinical significance, prognostic implications, and management modalities remain unclear, constituting still interesting topics for further investigations. Likewise, Young and Claassen (6) raised a crucial question; does NCSE merely reflect an epiphenomenon of severe brain injury or does it warrant detection and treatment in itself?. The response to this question in patients with suspected NCSE presenting with electrophysiologic findings of PDs may be particularly interesting and challenging as well.

Herein, we illustrate a remarkable patient with herpes encephalitis who neurologically deteriorated after convulsive seizures and EEG showed GPD that was compatible with NCSE. 


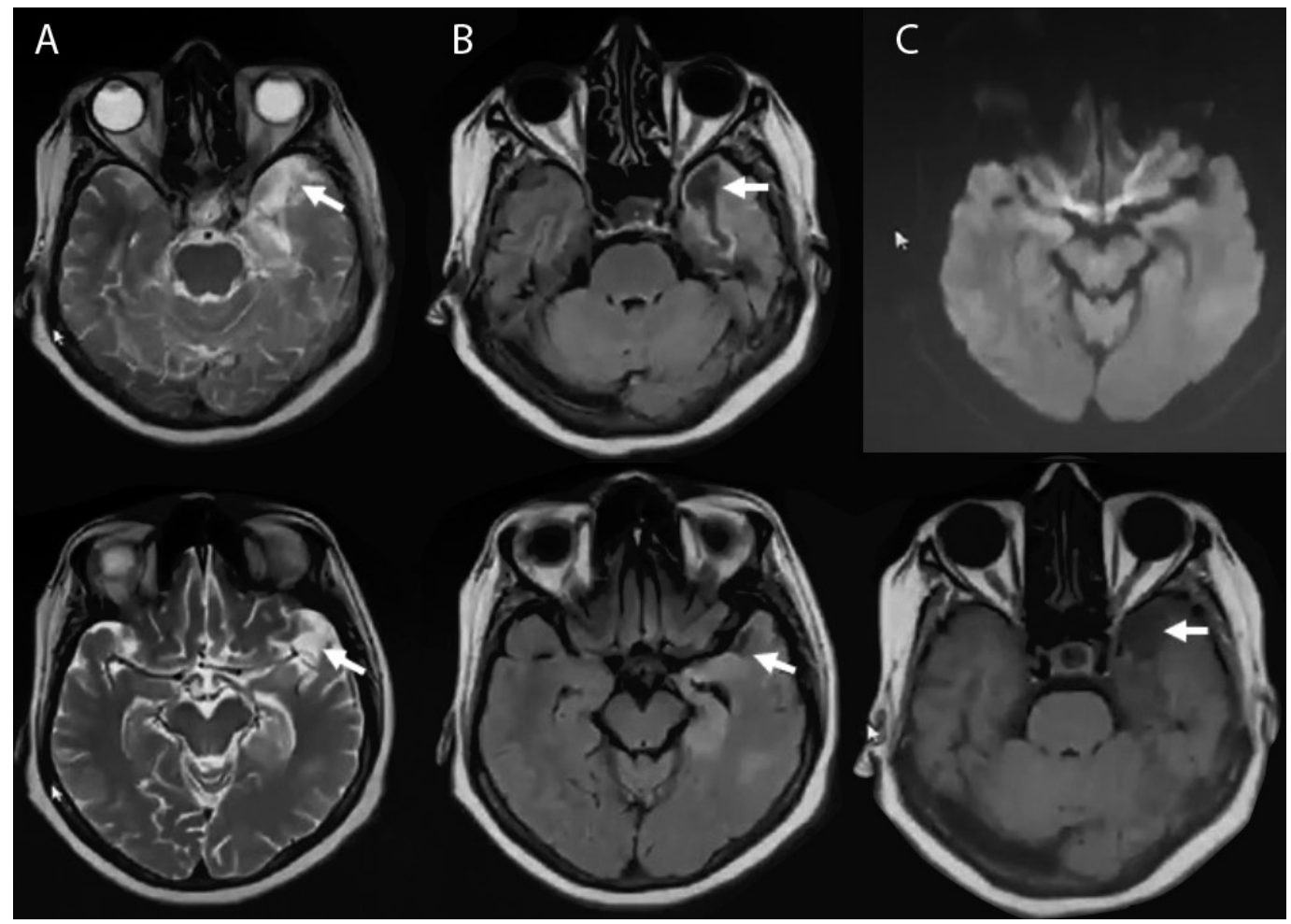

Figure 7. Contrast-enhanced magnetic resonance imaging performed on the $28^{\text {th }}$ day of admission, before discharge. A) T2-weighted images showing vasogenic lesion in the left anterior temporal lobe. Regression of expansion in the interval period is apparent. B) FLAIR sequences. C) Diffusion-weighted imaging and T1 images (arrows)

After the intervention of the multiple anti-epileptic drugs, the neurologic status of the patient gradually improved and concurrently performed EEG results showed a clear correlation with the clinical findings. Such that, on the next day, EEG showed resolution of LPD activity in the right hemisphere and she could open her eyes, lateralize painful stimulus with her left hand, supporting regaining of the right hemisphere function. On the following course, periodic activity in the left hemisphere was resolved and concurrently performed neurologic evaluations showed that the patient was orientated and cooperated. In addition, the right-sided paralysis recovered showing the re-function of the left hemisphere. In our opinion, this case represents a strictly detailed illustration of a patient with NCSE in whom PDs were the responsible disturbances and the neurologic clinic of the patient improved properly showing a clear correlation with EEG data, neuroanatomically. Cranial MRI showed edematous lesion limited to the left frontotemporal lobe and noninvolvement of the right hemisphere. However, EEG showed PDs also in the right hemisphere in the acute period, and a neurologic examination showed a neurologic status compatible with bi-hemispheric malfunction. Via the illustration of this case and related literature review, we demonstrate PD as a crucial electrophysiologic finding of NCSE that should be recognized by physicians. We also emphasize the importance of urgent intervention of AETs because EEG abnormalities may contribute to clinical manifestations substantially, which was demonstrated clearly in this case.
Overall, we think that multimodal evaluation (electrophysiologic, neuroradiologic, and clinical) of the patients is critical for reaching the correct diagnosis as well as guiding for the appropriate treatment. On the other hand, although the clinical significance of PD in the acute period has been rather acknowledged in a select patient group with NCSE (as in our case), its relevance in the prognosis of patients and the long-term benefits of AET have not been demonstrated to date (6). Future reports including serial EEG findings and long-term clinical data of these rare patients, presenting with $\mathrm{PD}$, are surely warranted to clarify the discussions mentioned above. The results of these studies may also add crucial contributions to our understanding of the unknown mechanisms underlying PD.

\section{Ethics}

Informed Consent: The informed consent form has been obrainted from the patient.

Peer-review: Internally peer-reviewed.

\section{Authorship Contributions}

Surgical and Medical Practices: H.Ö., F.T., Concept: H.Ö., Design: H.Ö., Data Collection or Processing: H.Ö., F.T., Analysis or Interpretation: H.Ö., F.T., Literature Search: H.Ö., Writing: H.Ö.

Conflict of Interest: No conflict of interest was declared by the authors.

Financial Disclosure: The authors declared that this study received no financial support. 


\section{References}

1. Chong DJ, Hirsch LJ. Which EEG patterns warrant treatment in the critically ill? Reviewing the evidence for treatment of periodic epileptiform discharges and related patterns. J Clin Neurophysiol 2005;22:79-91.

2. Garzon E, Fernandes RM, Sakamoto AC. Serial EEG during human status epilepticus: evidence for PLED as an ictal pattern. Neurology 2001;57:11751183.

3. Hirsch LJ, Brenner RP, Drislane FW, So E, et al. The ACNS subcommittee on research terminology for continuous EEG monitoring: proposed standardized terminology for rhythmic and periodic EEG patterns encountered in critically ill patients. J Clin Neurophysiol 2005;22:128-135.

4. Garcia-Morales I, Garcia MT, Galan-Davila L, et al. Periodic lateralized epileptiform discharges: etiology, clinical aspects, seizures, and evolution in 130 patients. J Clin Neurophysiol 2002;19:172-177.

5. van Putten MJ, Hofmeijer J. Generalized periodic discharges: Pathophysiology and clinical considerations. Epilepsy Behav 2015;49:228-233.

6. Young GB, Claassen J. Nonconvulsive status epilepticus and brain damage: further evidence, more questions. Neurology 2010;75:760-761. 